\title{
Easy Route to Functionalize Iron Oxide Nanoparticles via Long-Term
}

\author{
Stable Thiol Groups
}

\author{
L. Maurizi, H. Bisht, F. Bouyer*, N. Millot* \\ Institut Carnot de Bourgogne, UMR 5209 CNRS - Université de Bourgogne, BP 47870, 21078 Dijon cedex, France
}

The functionalization of superparamagnetic iron oxide nanoparticles (SPIOs) by meso-2,3-dimercaptosuccinic acid (DMSA) was investigated. Under ambient conditions, the thiol groups from DMSA are not stable and do not allow a direct functionalization without storage in stringent conditions or a chemical regeneration of free thiols. In this study, we have developed a protocol based on poly(ethylene glycol) (PEG) grafting of SPIO prior to DMSA anchoring. We have observed that PEGhelps to increase the stability of thiol groups under ambient conditions. The thiol functionalized SPIOs were stable under physiological pH and ionic strength as determined by Ellman's essay and allowed us to graft a thiol reactive fluorescent dye: tetramethylrhodamine-5maleimide (TMRM).

Superparamagnetic iron oxide (SPIO) nanoparticles have received great attention for a few decades in the fields of bioapplications such as early diagnostics ${ }^{1}$ or treatment of diseases like cancer. ${ }^{2}$ Most often, SPIOs are synthesized by aqueous coprecipitation method and the surface chemistry of the nanoparticles is governed by the FeOH surface groups. As a result, SPIOs are neutral in the physiological conditions and agglomerate very quickly. ${ }^{3}$ To prevent this process, various hydrophilic polymers have been attached to sterically stabilize the colloids. ${ }^{4,5}$ Polyethylene glycol (PEG) is one of the most common polymers used due to its high hydrophilicity and biocompatibility. ${ }^{4,6}$ Covalently attached PEG can stabilize the SPIO for long duration at rigorous physiological conditions. ${ }^{7}$ In the fields of biosensing or bioimaging, biomolecules can be covalently grafted onto iron oxide nanoparticles via disulfide bonds. As an example, meso-2,3-dimercaptosuccinic acid (DMSA) provides an easy way to functionalize SPIO with thiol groups ${ }^{8,9,10}$ but their oxidation to polysulfide is hardly prevented. ${ }^{10}$ To circumvent the formation of disulfide bonds between the DMSA molecules, coated SPIOs have to be stored in inert conditions and/or at low temperature. Otherwise dithiothreitol (DTT) or tris-(2-carboxyethyl)-phosphine (TCEP) are to be used prior to bio functionalization to regenerate the thiols. ${ }^{11}$ Finally, a high concentration of DMSA is needed to have at least one free thiol on SPIO but excessive amount of DMSA should be avoided as it is used as a drug to prevent heavy metals toxicity. ${ }^{12}$

The present paper reports a convenient method to stabilize free thiols onto SPIOs by post functionalization using methoxyPEG 2000 silane. The stability was proved by grafting a thiol reactive dye: tetramethylrhodamine-5-maleimide (TMRM). ${ }^{13}$

Iron oxide nanoparticles were synthesized by coprecipitation method as described in the literature. ${ }^{14}$ Briefly, a $1: 2$ molar ratio of ferrous and ferric chloride (respectively $1 \mathrm{M}$ and $2 \mathrm{M}$ ) was added dropwise to a $0.75 \mathrm{M} \mathrm{NaOH}$ solution at $90{ }^{\circ} \mathrm{C}$. After washing, the final product was kept at $\mathrm{pH} 3$ with a SPIO concentration of $23 \mathrm{mg} / \mathrm{mL}$. The crystallite size of the nanoparticles given by XRD $(7.6 \pm 0.1) \mathrm{nm}$ is in close agreement with the mean TEM grain size $(9 \pm 1) \mathrm{nm}$ (Figure 1). The specific surface area of SPIOs is $(110 \pm 1) \mathrm{m}^{2} / \mathrm{g}$.

\footnotetext{
* Corresponding authors. E-mail: nmillot@u-bourgogne.fr, bouyerf@u-bourgogne.fr
}

(1) (a) Babes, L.; Denizot, B.; Tanguy, G.; Le Jeune, J. J.; Jallet, P. J. Colloid Interf. Sci. 1999, 212, 474-482. (b) Bulte, J. W. M.; Kraitchman, D. L. NMR Biomed. 2004, 17, 484499. (c) Huh, Y. M.; Jun, Y. W.; Song, H. T.; Kim, S.; Choi, J. S.; Lee, J. H.; Yoon, S.; Kim, K. S.; Shin, J. S.; Suh, J. S.; Cheon, J. J. Am. Chem. Soc. 2005, 127, 1238712391. (d) Mornet, S.; Vasseur, S.; Grasset, F.; Duguet, E. J.Mater. Chem. 2004, 14, 2161-2175. (e) Wang, Y. X. J.; Hussain, S. M.; Krestin, G. P. Eur. Radiol. 2001, 11, 2319-2331. (f) Zhao, M.; Beauregard, D. A.; Loizou, L.; Davletov, B.; Brindle, K. M. Nat. Med. 2001, 7, 1241-1244.

(2) (a) Fortin, J.-P.; Gazeau, F.; Wilhelm, C. Eur. Biophys. J. Biophy. 2008, 37, 223-228. (b) Hiergeist, R.; Andra, W.; Buske, N.; Hergt, R.; Hilger, I.; Richter, U.; Kaiser, W. J. Magn. Magn. Mater. 1999, 201, 420-422. (c) Jordan, A.; Scholz, R.; Wust, P.; Schirra, H.; Schiestel, T.; Schmidt, H.; Felix, R. J. Magn. Magn. Mater. 1999, $194,185-196$.

(3) Jolivet, J.-P., Metal Oxide Chemistry and Synthesis : From solution to solid state. 3rd ed.; 1994; Vol. 25, p 338.

(4) Kohler, N.; Fryxell, G. E.; Zhang, M. Q. J. Am. Chem. Soc. 2004, 126, 7206-7211.

(5) (a) Makhluf, S. B. D.; Abu-Mukh, R.; Rubinstein, S.; Breitbart, H.; Gedanken, A. Small 2008, 4, 1453-1458. (b) Schulze, K.; Koch, A.; Petri-Fink, A.; Steitz, B.; Kamau, S.; Hottiger, M.; Hilbe, M.; Vaughan, L.; Hofmann, M.; Hofmann, H.; von Rechenberg, B. J. Nanosci. Nanotechno. 2006, 6, 2829-2840. (c) Thunemann, A. F.; Schutt, D.; Kaufner, L.; Pison, U.; Mohwald, H. Langmuir 2006, 22, 2351-2357. (d) Veiseh, O.; Sun, C.; Gunn, J.; Kohler, N.; Gabikian, P.; Lee, D.; Bhattarai, N.; Ellenbogen, R.; Sze, R.; Hallahan, A.; Olson, J.; Zhang, M. Q. Nano Lett. 2005, 5, 1003-1008.

(6) (a) Gupta, A. K.; Curtis, A. S. G. J. Mater. Sci-Mater.M. 2004, 15, 493-496. (b) Li, Z.; Tan, B.; Allix, M.; Cooper, A. I.; Rosseinsky, M. J. Small 2008, 4, $231-239$.

(7) (a) Lee, H.; Lee, E.; Kim, D. K.; Jang, N. K.; Jeong, Y. Y.; Jon, S. J. Am. Chem. Soc. 2006, 128, 7383-7389. (b) Lee, K.; Cheong, C.; Hong, K. S.; Koh, E. K.; Kim, M.; Shin, H. S.; Kim, Y. N.; Lee, S. H. J. Korean Phys. Soc. 2008, 53, 2535-2539. (c) Weissleder, R.; Bogdanov, A.; Neuwelt, E. A.; Papisov, M. Adv. Drug Deliver Rev. 1995, 16, 321334.

(8) Cheon, J. W.; Jun, Y. W.; Choi, J. S. Water-soluble magnetic or metal oxide nanoparticles coated with ligands. KR Patent 100713745 , WO2007097605, 2007.

(9) Fauconnier, N.; Pons, J. N.; Roger, J.; Bee, A. J. Colloid Interf. Sci. 1997, 194, 427-433.

(10) Roger, J.; Pons, J. N.; Massart, R.; Halbreich, A.; Bacri, J. C. Eur. Phys. J-Appl. Phys. 1999, 5, 321-325.

(11) (a) Getz, E. B.; Xiao, M.; Chakrabarty, T.; Cooke, R.; Selvin, P. R. Anal. Biochem. 1999, 273, 73-80. (b) Leal, W. S.; Nikonova, L.; Peng, G. FEBS Lett. 1999, 464, 85-90. (c) Lykkesfeldt, Anal. Biochem. 2000, 282, 89-93. (d) Schouten, A.; Roosien, J.; Bakker, J.; Schots, A. J. Biol. Chem. 2002, 277, 19339-19345.

(12) Domingo, J. L. Reprod. Toxicol. 1995, 9, 105-113.

(13) Cissell, K. A.; Shrestha, S.; Purdie, J.; Kroodsma, D.; Deo, S. K. Anal. Bioanal. Chem. 2008, 391, 1721-1729.

(14) (a) Massart, R. IEEE T. Magn. 1981, 17, 1247-1248. (b) Bouyer, F.; Bisht, H.; Maurizi, L.; Millot, N. to be submitted 2009. 
To prepare DMSA coated SPIOs (DMSA-SPIO), $22 \mathrm{mg}$ of DMSA dissolved in degassed water were mixed to $100 \mathrm{mg}$ of SPIO dispersion at $\mathrm{pH} 3$ under nitrogen flow to prevent the formation of disulfide bonds. The reaction mixture was stirred at room temperature for 2 hours.

After washing, DMSA-SPIO suspension was stored under nitrogen at $4{ }^{\circ} \mathrm{C}$.

To functionalize iron oxide nanoparticles with $\mathrm{mPEG}_{2000}$ (mPEG-SPIO), a silanated methoxy polyethylene glycol (mPEG ${ }_{2000^{-}}$ $\mathrm{Si}$ ) was synthesized as described in the literature. ${ }^{15}$ Briefly, 3-isocyanatopropyltriethoxysilane was attached to $\mathrm{mPEG}_{2000}$, using dibutyltindilaurate, at $60{ }^{\circ} \mathrm{C}$ in dried THF under nitrogen flow for 48 hours. $\mathrm{mPEG}_{2000}$-Si was precipitated in n-hexane. Then 400 $\mathrm{mg}$ of $\mathrm{mPEG}_{2000}-\mathrm{Si}$ (molecular weight $\sim 2250 \mathrm{~g} / \mathrm{mol}$ ) was dissolved in $40 \mathrm{~mL}$ of ethanol/water mixture $(50 / 50 \mathrm{v} / \mathrm{v}, \mathrm{pH} 4.0)$ and 100 $\mathrm{mg}$ of SPIO dispersion was added to the polymer solution. After 48 hours the reaction mixture was dialyzed and freeze dried before use.

For the bifunctionalization of SPIOs (mPEG-SPIO-DMSA) $7.7 \mathrm{mg}$ of DMSA was added to a suspension containing $500 \mathrm{mg}$ of mPEG-SPIO and was stirred for 2 days. The purification of mPEG-SPIO-DMSA was done by washing with dilute HCl solution (pH 3). The samples were stored under ambient conditions.

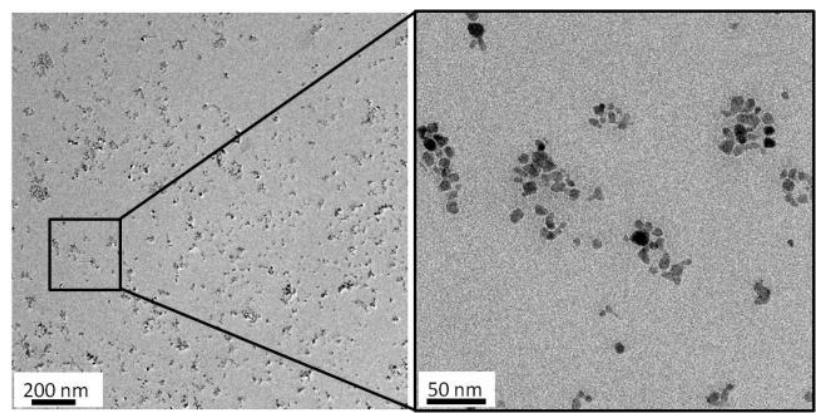

Figure 1. TEM images of bare SPIO nanoparticles

Six weeks after the synthesis of bifunctionalized SPIOs tetramethylrhodamine-5-maleimide (TMRM) was added to mPEGSPIO-DMSA in water at $\mathrm{pH} 7.5$ with five times molar excess of TMRM - previously dissolved in DMSO - and stirred at room temperature for 24 hours. Excess of dye by removed by dilute $\mathrm{HCl}$ washing $(\mathrm{pH} 3)$ and the suspension was analyzed by UV-visible spectrometry, then kept at $-18^{\circ} \mathrm{C}$ in the dark.

As a matter of comparison, TMRM was added 24 hours after synthesis of DMSA-SPIO in water at pH 7.5 and stirred at room temperature for 24 hours. After removal of excess TMRM the suspension was analyzed by UV-visible spectrometry.

DMSA-SPIOs formed stable dispersion in $0.15 \mathrm{M} \mathrm{NaCl}$ solution from $\mathrm{pH} 4$ to $\mathrm{pH} 11$. Dynamic light scattering experiments showed a mean hydrodynamic diameter of $50 \mathrm{~nm}$ in this range of $\mathrm{pH}$. Furthemore the nanoparticles are negatively charged due to the carboxylate groups of DMSA. However, the thiol groups could not be detected by Ellman's reagent (in PBS 20 mM solution) even just after synthesis (Table 1). It has been reported in the literature that DMSA forms tetramers on the surface of nanoparticles. ${ }^{9}$ Indeed these tetramers once adsorbed on the surface can form polysulfides very quickly due to close proximity of intermolecular thiol groups as observed in the template polymerization of sulfides. ${ }^{10}$

When DMSA was added to mPEG-SPIO nanoparticles, a stable suspension was observed in $0.15 \mathrm{M}$ of $\mathrm{NaCl}$ whatever the pH and the mean hydrodynamic diameter was approximately the same than previously observed. The zeta potential of the nanoparticles was negative for all the $\mathrm{pH}$, for the same reasons than previously explained. But free thiols were sterically protected by the polymer chains and hence Ellman's reagent was able to detect thiol groups even 10 weeks after storage under ambient conditions (see Table $1)$.

\begin{tabular}{cccccc}
\hline & & \multicolumn{4}{c}{ Molecules/nm² after grafting after } \\
Molecule & Nanoparticles & 1 day & 1 week & 6 & 10 \\
& weeks & weeks \\
\hline DMSA & Bare SPIO & 0 & 0 & 0 & 0 \\
DMSA & mPEG-SPIO & nd & $\mathbf{0 . 1 9}$ & $\mathbf{0 . 1 4}$ & $\mathbf{0 . 1 4}$ \\
TMRM & DMSA-SPIO & 0 & nd & nd & nd \\
TMRM & mPEG-SPIO- & nd & nd & $\mathbf{0 . 2 8}$ & $\mathbf{0 . 2 8}$
\end{tabular}

Table 1. UV-visible titration of DMSA (using Ellman's reagent) or TMRM on bare and functionalized SPIO

The detection of thiols was then correlated with the estimation of grafted TMRM both by UV visible absorbance at respectively $412 \mathrm{~nm}$ and $555 \mathrm{~nm}$ (Table 1). After storing mPEG-SPIO-DMSA suspension for 6 weeks under ambient conditions, the average number of thiol groups per $\mathrm{nm}^{2}$ was about $\mathbf{0 . 2 8}$, which means $\mathbf{0 . 1 4}$ DMSA molecules per $\mathrm{nm}^{2}$ (see Table 1). 0.28 TMRM molecules were grafted per $\mathrm{nm}^{2}$ of SPIO which proved the accessibility of all free thiols and the ability to graft active molecules on there. Scheme 1 shows what could happen when $\mathrm{mPEG}_{2000}-\mathrm{Si}$ protects thiols of DMSA. These results show a good correlation between still active thiols and grafted TMRM.

In the case of DMSA-SPIO, no grafted TMRM was detected by UV-visible spectrometry confirming the absence of free thiols on the SPIO surface. 


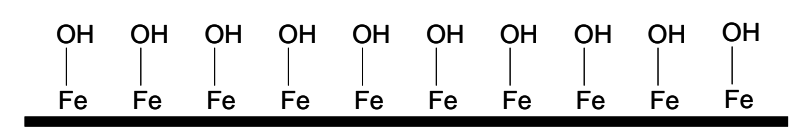

SPIO with surface hydroxyl groups

ethanol/water (50/50)
$\mathrm{RT}, 48 \mathrm{~h}, \mathrm{pH} 4.0$
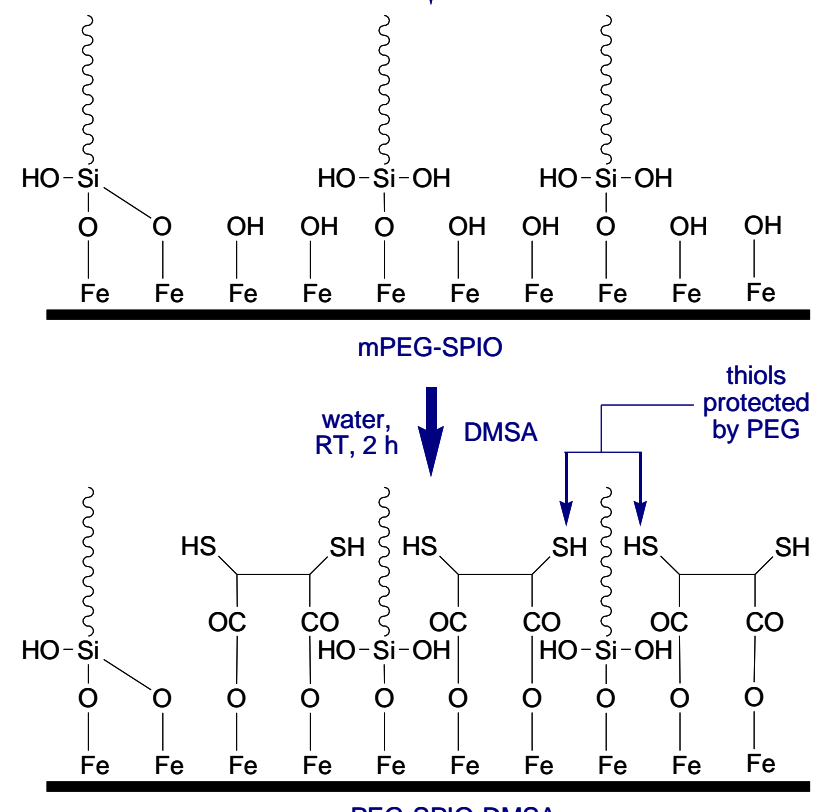

mPEG-SPIO-DMSA

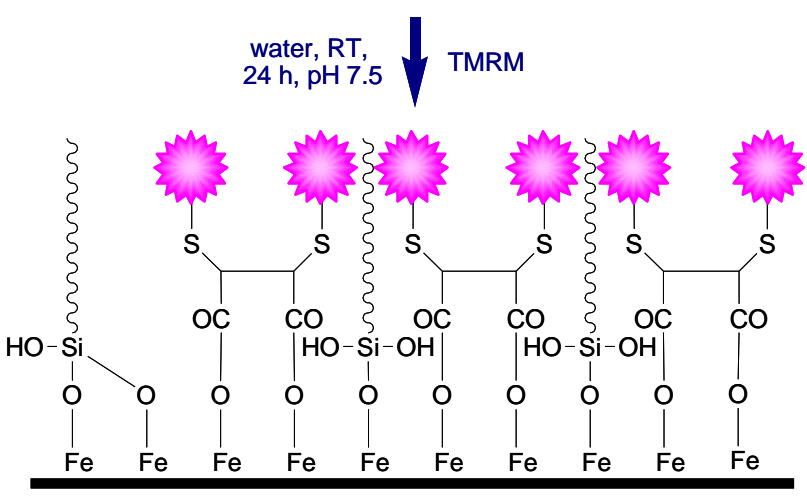

TMRM grafted on mPEG-SPIO-DMSA

Figure 2. Strategy for protection of thiol groups

In this study, we have shown that the stability of thiols can be increased significantly when DMSA is protected by PEG chains on the surface of SPIOs. The thiol groups of DMSA were stable even after 10 weeks of storage under ambient conditions. These thiols can be used to attach proteins or thiol reactive dyes without using DTT or stringent storage conditions. Furthermore mPEGSPIOs-DMSA are stable at physiological conditions. Then this synthesis allows to manipulate well dispersed nanoobjects with functionalizable sites for a long period of time compared to the classical strategies.

Acknowledgments. We gratefully thank Dr. R. Chassagnon for TEM experiments and the Conseil Régional de Bourgogne for financial support. 